\title{
A technical note on the phase transformation in furnace container material after a periodic thermo-chemical treatment
}

\author{
A.J.R. Loureiro ${ }^{a}$, B.F.O. Costa ${ }^{b}$,* \\ ${ }^{a}$ Departamento de Engenharia Mecânica (CEMUC), Universidade de Coimbra, P-3030 Coimbra, Portugal \\ ${ }^{\mathrm{b}}$ Departamento de Física, Universidade de Coimbra, P-3000 Coimbra, Portugal
}

Received 10 August 2001; accepted 2 January 2002

\begin{abstract}
The aim of this work is to investigate the metallurgical changes in the wall of cylindrical containers, fabricated by welding from AISI 310 steel, used in the thermal and chemical treatment of spindle chains for the automotive industry, for an in-service period of over $1000 \mathrm{~h}$. In order to identify the phases originated during this in-service period, several etchants were used in the structural study, together with X-ray diffraction and ${ }^{57} \mathrm{Fe}$ Mössbauer spectroscopy analysis. The metallographic technique demonstrates some limitations in the complete identification of the phases produced in the wall of the containers. The structure of the wall of the containers, after the referred to working period, is composed of an austenitic matrix, whose grain size is about 212 and $238 \mu \mathrm{m}$, near the internal and external faces of the wall, respectively. These show numerous precipitates inside the grains and at the grain boundaries. The density of the precipitates decreases from the internal to the external surface. The precipitates are nitrides $(\mathrm{Cr}, \mathrm{Mo})_{12}(\mathrm{Fe}, \mathrm{Ni})_{8-x} \mathrm{~N}_{4-z}$ near the internal surface, and carbides $(\mathrm{Cr}, \mathrm{Fe}$, $\mathrm{Mo}_{23} \mathrm{C}_{6}$ on the other zones of the wall. (C) 2002 Elsevier Science B.V. All rights reserved.
\end{abstract}

Keywords: AISI 310; Phase transformation; Carbides; Nitrides; Mössbauer; X-ray diffraction

\section{Introduction}

Austenitic stainless steels are widely used in industry due to its corrosion resistance, but also in applications at elevated temperature, some of them being sometimes referred to as heat-resistant steels. The elevated temperature behaviour of these steels depends largely on the specific characteristics such as oxidation resistance, type of oxide scale, thermal conductivity and thermal expansion as well as on the working conditions $[1,2]$. The degradation of these steels when exposed at elevated temperature generally occurs due to precipitation reactions and/or environmental effects, like oxidation or carburisation [2,3]. The precipitation reactions are a complex function of the chemical composition of the material and the operating temperature and eventually of the working environment [3].

The aim of the work to investigate the metallurgical changes in the wall of cylindrical containers, produced in a austenitic stainless steel AISI 310 S and used in the thermal chemical treatment of spindle chains for the automotive industry, as they seem to be responsible for the premature failure of these equipment.

\footnotetext{
* Corresponding author.

E-mail address: benilde@ci.uc.pt (B.F.O. Costa).
}

\section{Experimental procedure}

Three containers were fabricated by welding in AISI 310S steel with a wall of $8 \mathrm{~mm}$ thickness and subjected to a periodic thermal cycle, consisting of a heating up to $970{ }^{\circ} \mathrm{C}$, followed by a stage of $4 \mathrm{~h}$ at this temperature and a slow cooling down period to room temperature in calm atmosphere of approximately $9 \mathrm{~h}$. The heating operation is carried out using a propane gas burner. Inside the container there is a cement mixture of $\mathrm{Cr}, \mathrm{Al}_{2} \mathrm{O}_{3}$ and $\mathrm{NH}_{4} \mathrm{Cl}$ together with the spindles. After the thermal cycle each container is hammered and the cement, which has solidified during treatment, is broken in order to extract the chain pins. During all the cycles the container is rotating at a speed of $15 \mathrm{rpm}$. The first container was subjected to 250 cycles operation, the second to 300 cycles and the third to 350 cycles, corresponding, respectively, to 1000,1200 and $1400 \mathrm{~h}$ working at $970{ }^{\circ} \mathrm{C}$.

Afterwards specimens were extracted from the wall containers, ground, polished using 3 and $1 / 2 \mu \mathrm{m}$ diamond paste and examined under a reflection light microscope.

The chemical composition of the samples was determined by wavelength dispersive spectrometry, using an electron probe microanalyser Camebax SX 50, with a focus of $250 \mu \mathrm{m} \times 250 \mu \mathrm{m}$ 
Different etchants were used to identify the phases present in the specimens. Ammonium persulfate $\left[10 \mathrm{~g}\left(\mathrm{NH}_{4}\right)_{2} \mathrm{~S}_{2} \mathrm{O}_{8}+\right.$ $100 \mathrm{ml} \mathrm{H}_{2} \mathrm{O}$ ] was used to reveal carbides, according to [4]. Two other etchants, specifically to reveal the $\sigma$ phase, were also used. The reagents employed were potassium hydroxide $\left[56 \mathrm{~g} \mathrm{KOH}+100 \mathrm{ml} \mathrm{H}_{2} \mathrm{O}\right]$ and sodium cyanide $[10 \mathrm{~g} \mathrm{NaCN}+$ $100 \mathrm{ml} \mathrm{H}_{2} \mathrm{O}$ ] [4].

${ }^{57} \mathrm{Fe}$ Mössbauer spectra were registered at room temperature in a transmission geometry with a ${ }^{57} \mathrm{Co} / \mathrm{Rh}$ source of about $15 \mathrm{mCi}$. To prepare the Mössbauer samples, the stainless steel container walls were powdered $(\approx 60 \mu \mathrm{m}$ diameter $)$ by means of a diamond file. Different areas of the steel plates, relevant to our area of study, were investigated. The evaluation of the spectra was carried out, using a least-square-minimum computer fitted to a superposition of Lorentzian shaped lines. The samples used for Mössbauer spectroscopy were the same as those used in X-ray diffraction measurements. The X-ray diffraction patterns were obtained at room temperature using $\mathrm{Cr} \mathrm{K} \alpha$ radiation $(\lambda=0.229090 \mathrm{~nm})$.

\section{Results and discussion}

Container undergoing a working period of $1000 \mathrm{~h}$ do not show any crack in the surface; however, in the other two containers some cracks nucleated on the external surface of the container growing through the wall towards the internal surface. The same type of cracks was observed in the weld metal and in the parent plate. In the container running $1400 \mathrm{~h}$ some cracks crossed though the wall. The appearing of the cracks may be attributed to the formation of brittle structures, which form during the operating period. The same type of metallurgical structures was observed in the three containers independent of the working time.

\subsection{Chemical composition}

The mean chemical composition of the specimens extracted from the parent plate is identical to that of the specimens obtained from the furnace containers, after approximately $1000 \mathrm{~h}$ of work. The mean composition is indicated in Table 1.

A scanning line chemical composition analysis, through the wall thickness of the samples obtained from the furnace containers, showed that it undergoes significant change from the inside surface to the external surface. Near the internal surface the chromium and nitrogen contents increase due to the diffusion of these elements from the cement, and there is also a depletion of Ni, as illustrated in Fig. 1.

Table 1

Mean chemical composition of the parent plate (balance Fe)

\begin{tabular}{llllll}
\hline $\mathrm{C}($ wt.\%) & $\mathrm{Si}(\mathrm{wt} . \%)$ & $\mathrm{Mn}($ wt.\%) & $\mathrm{Ni}($ wt.\%) & $\mathrm{Cr}$ (wt.\%) & Mo (wt.\%) \\
\hline 0.05 & 2.2 & 1.2 & 18.9 & 24.8 & 0.39 \\
\hline
\end{tabular}

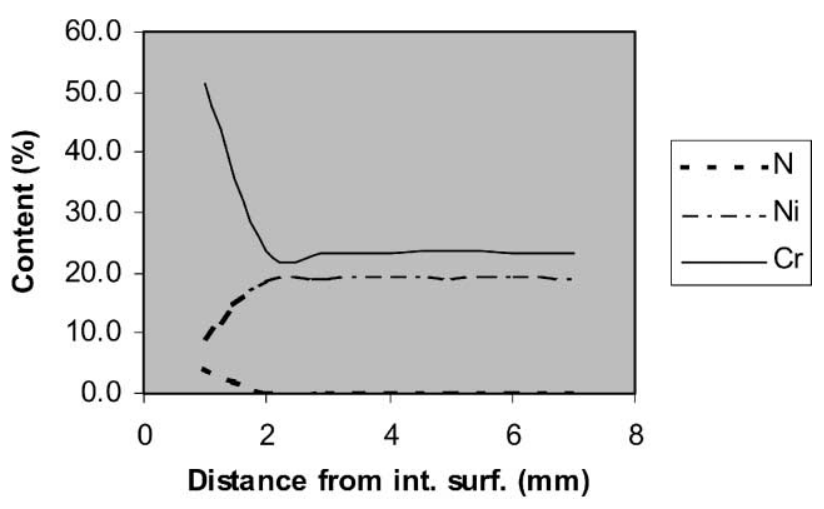

Fig. 1. Variation of the chemical composition through the wall thickness of the containers.

\subsection{Metallographic study}

The variation of the chemical composition through the wall thickness is accompanied by some change in the microstructure. Two types of alterations are noticedchange in the grain size of the matrix and change in the shape, size and density of the precipitates.

Fig. 2(a)-(c) shows the microstructure through the wall thickness, revealed by using the etchant ammonium persulfate. The structure observed is composed of an austenitic matrix with numerous second phase particles, precipitated inside the grains and at the grain boundaries. The precipitates observed at half thickness and close to the external surface of the wall might be carbides, as ammonium persulfate tends to colour carbide dark brown [4]. The precipitates near the internal surface of the wall are not coloured but only outlined, suggesting they are not carbides.

The decrease in the number of the precipitates, from the internal to the external surface of the wall of the containers, is also obvious from Fig. 2. A marked increase in the grain size of the matrix, occasioned by the thermal cycles induced during the heat treatment, may also be observed. The average grain size of the parent plate is $30 \mu \mathrm{m}$ while that of the container is $212 \mu \mathrm{m}$ near the internal surface and $238 \mu \mathrm{m}$ close to the external surface.

The structures revealed near the internal surface using the sodium cyanide and potassium hydroxide etchants are illustrated in Fig. 3(a) and (b), respectively. Sodium cyanide generally darkens the sigma phase and light darkens carbides. The heavy darkening of the precipitates exhibited in Fig. 3(a) suggests they are sigma phase. This observation is contradictory with the conclusion above.

Fig. 3(b) shows the structure revealed with potassium hydroxide etchant. Potassium hydroxide generally colours the sigma phase reddish brown [4] but this fact was not observed in this case, which calls into question the existence of the sigma phase in this part of the wall.

The facts referred to above show that the metallographic technique presents some limitations in the identification of the phases produced in the wall of the containers. 


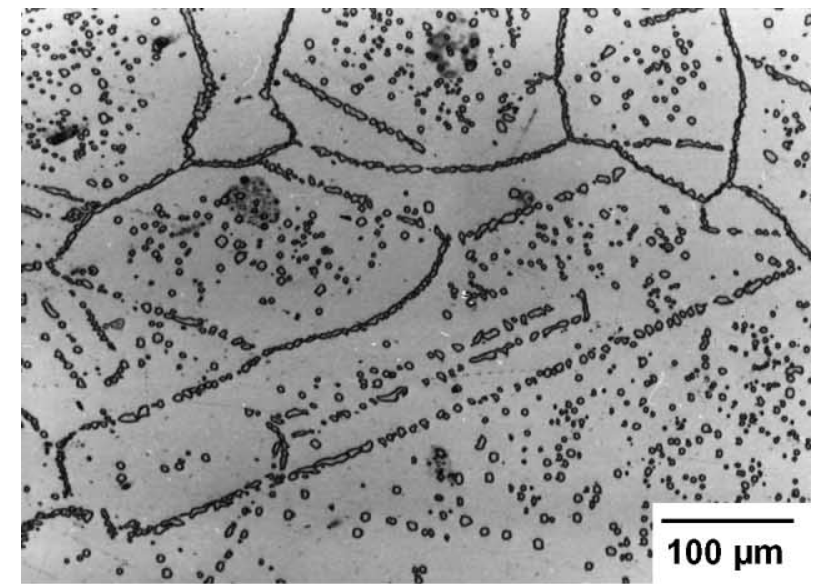

(a)

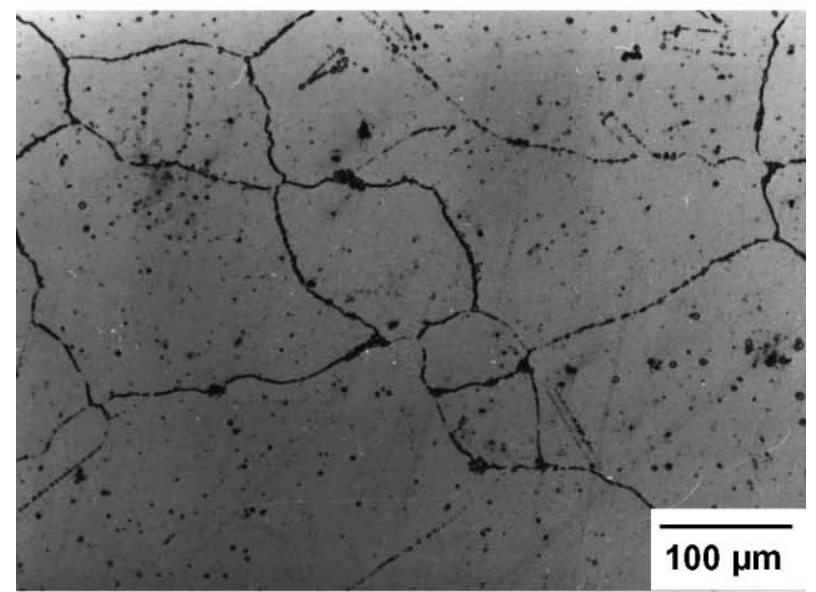

(b)

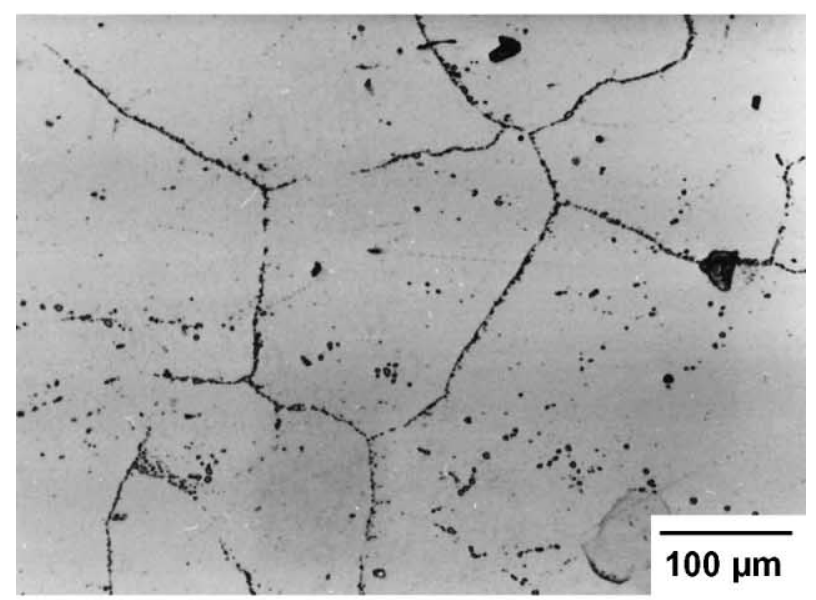

(c)

Fig. 2. Microstructure through the wall of a container (ammonium persulfate, $30 \mathrm{~s}$ ): (a) close to the internal surface; (b) at half thickness; (c) near the external surface.

\subsection{Mössbauer spectroscopy and X-ray diffraction}

The results obtained above, using metallographic techniques, highlight the necessity to use other methods to identify the structures formed in the wall of the containers.

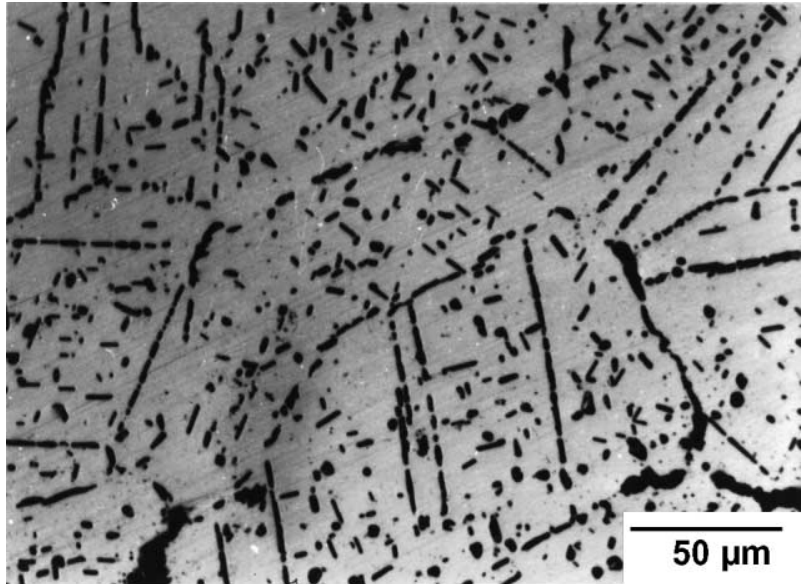

(a)

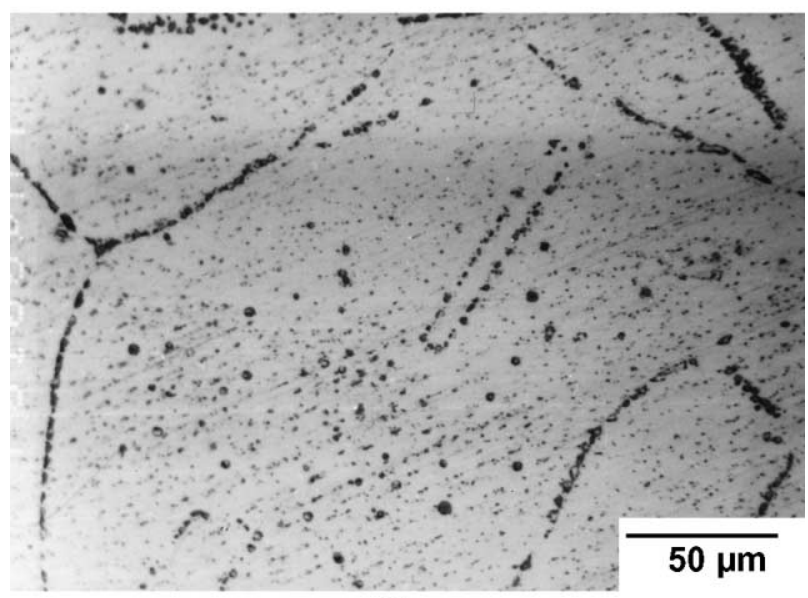

(b)

Fig. 3. Structures revealed near the internal surface of the wall with the following etchants: (a) sodium cyanide etchant $(10 \mathrm{~g} \mathrm{NaCN}+100 \mathrm{ml}$ $\left.\mathrm{H}_{2} \mathrm{O}, 6 \mathrm{~V}, 30 \mathrm{~s}\right)$; (b) potassium hydroxide etchant $(56 \mathrm{~g} \mathrm{KOH}+100 \mathrm{ml}$ $\left.\mathrm{H}_{2} \mathrm{O}, 3 \mathrm{~V}, 3 \mathrm{~s}\right)$.

Mössbauer spectroscopy and X-ray diffraction techniques were selected in order to better characterise the phases present in the sample.

The advantage of using Mössbauer spectroscopy for this purpose is that it permits the detection of the sigma phase in the earliest stages of its formation, i.e. in the region that is normally not accessible to methods traditionally used in such studies as X-ray diffraction and electron microscopy. Both the sigma and the austenitic phases are paramagnetic at room temperature, their spectra consisting of a pseudosingle-line. However, the isomer shift (IS) of the spectrum characteristic of the sigma phase is larger in magnitude by a factor of 2, than that which is characteristic of the austenitic phase [5,6]; thus they are clearly distinguished.

Fig. 4 shows the Mössbauer spectra obtained for the external and internal faces of the furnace containers, as indicated. The spectra were fitted with a single peak and a doublet, which are also shown in the figure. The fitted parameters for the spectra are listed in Table 2. The values 


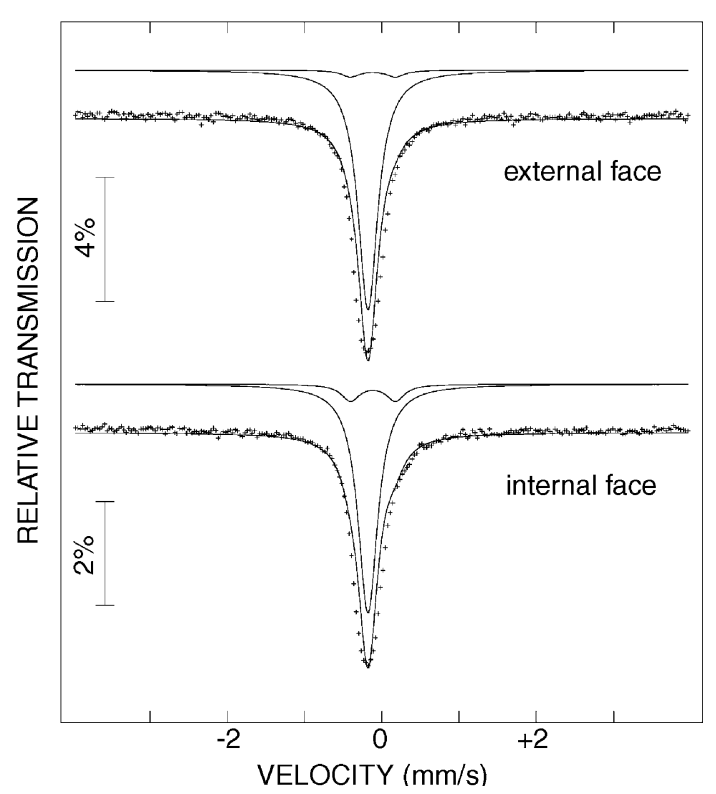

Fig. 4. Room temperature ${ }^{57} \mathrm{Fe}$ Mössbauer spectra of external and internal faces of the stainless steel furnace container.

Table 2

Best-fit values of spectral parameters as obtained from the ${ }^{57} \mathrm{Fe}$ Mössbauer spectra $^{\mathrm{a}}$

\begin{tabular}{|c|c|c|c|c|c|}
\hline & \multicolumn{2}{|l|}{ Single peak } & \multicolumn{3}{|l|}{ Doublet } \\
\hline & IS $(\mathrm{mm} / \mathrm{s})$ & $\%$ & IS (mm/s) & $\mathrm{QS}(\mathrm{mm} / \mathrm{s})$ & $\%$ \\
\hline External face & -0.065 & 95.2 & 0.0 & 0.60 & 4.8 \\
\hline Internal face & -0.066 & 88.5 & 0.0 & 0.60 & 11.5 \\
\hline
\end{tabular}

\footnotetext{
${ }^{\mathrm{a}}$ The meaning of the symbols is given in the text. The ISs are relative
} to $\alpha$-Fe. obtained for IS and quadrupole splitting (QS) agree well with those reported for austenitic alloys based on $\mathrm{Fe}-\mathrm{C}$ [6]. Table 2 also gives the component ratios (\%) of the single and double peaks for each spectrum. We have also fitted the spectra shown in Fig. 5, as well as those obtained from zones such as the external cracks of the wall and the half thickness, with only a single peak. The results of the IS were $-0.070,-0.067,-0.060$ and $-0.074 \mathrm{~mm} / \mathrm{s}$, respectively, for the external face, internal face, half thickness and cracks on the external face. In these cases, the line widths of the peak were approximately $0.43 \mathrm{~mm} / \mathrm{s}$. These values are similar to those obtained for the sigma phase, when its presence is below $20 \%$ [7]. We set aside the hypothesis of assigning these single peaks to the sigma phase not only because they are too broad but also because the cracks and the high fragility observed in the container wall are not consistent with this low percentage. Furthermore, the presence of $20 \%$ of the tetragonal sigma phase in the studied samples would be visible in X-ray diffraction patterns, which is not the case.

As the IS is sensitive to the composition of a given phase and to an arrangement of atoms in space, it is natural to obtain different values of IS for the different zones of the stainless steel of the container wall because the composition of the zones is different.

Fig. 5 shows X-ray diffractograms for different zones of a furnace container, from the internal face to the external face and the external cracked region, as indicated.

Besides the austenitic phase present in all the patterns, the peaks of the diffraction pattern of the internal face were indexed to be carbides $(\mathrm{Cr}, \mathrm{Fe})_{23} \mathrm{C}_{6}$, with a strong possibility of the presence of $(\mathrm{Cr}, \mathrm{Fe}, \mathrm{Mo})_{23} \mathrm{C}_{6}$, which leads to the

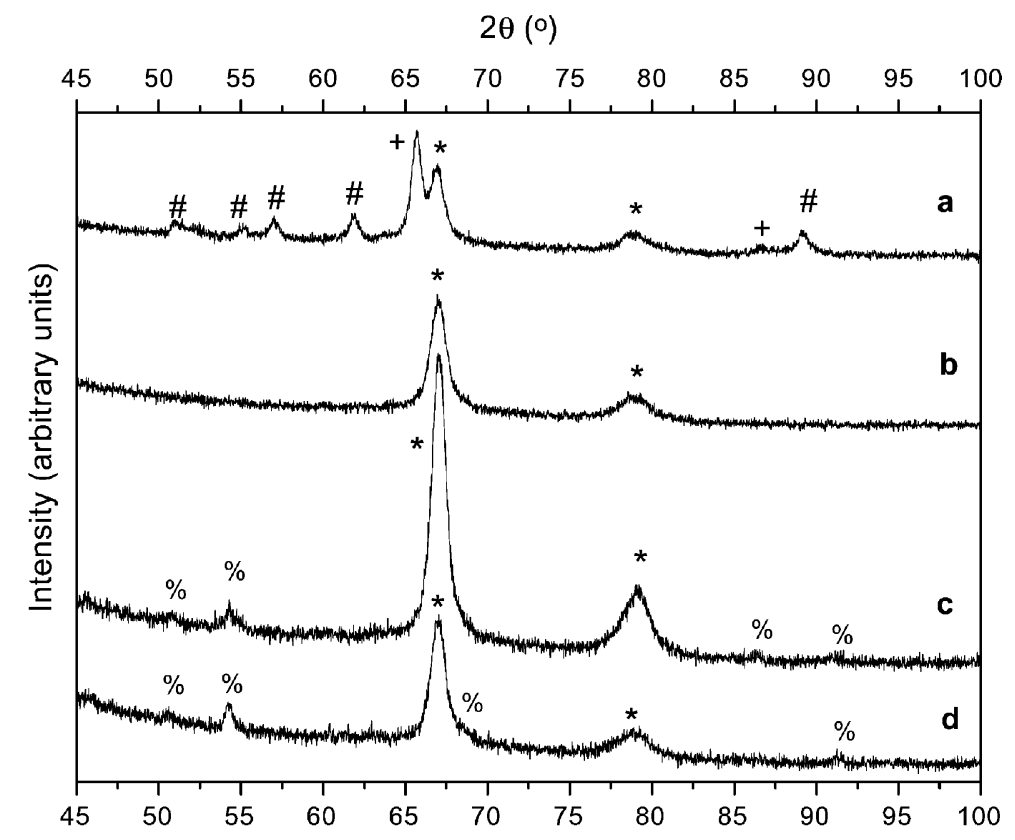

Fig. 5. Room temperature X-ray diffraction patterns from different areas of the furnace wall container: (a) internal face; (b) half thickness of the wall; (c) external face; (d) cracked region on external face. Indexed peaks: $*$ austenite, + nitrides, $\# \mathrm{M}_{23} \mathrm{C}_{6}, \% \mathrm{Fe}-\mathrm{Mo}$ carbides. 
distortion of the lattice. In this same diffraction pattern the existence of nitrides $(\mathrm{Cr}, \mathrm{Mo})_{12}(\mathrm{Fe}, \mathrm{Ni})_{8-x} \mathrm{~N}_{4-z}$ is also apparent.

At the half thickness of the wall, the austenitic phase can be clearly seen. On the external face iron-molybdenum carbides are present, and they are also observed in the cracked region.

The conclusions above were confirmed by chemical analysis of the precipitates and are referred to elsewhere [8].

The formation of carbides at this stage does not exclude the possibility of a subsequent formation of the sigma phase. According to Singhal and Martin [9] the formation of the sigma phase follows the consumption of ferrite, whose precipitation and growth is accompanied by the dissolution of the initially formed $\mathrm{M}_{23} \mathrm{C}_{6}$.

\section{Conclusions}

The structural analysis of the wall of the containers, after an operating period of over $1000 \mathrm{~h}$ was carried out. The metallographic technique presented some limitations in the complete identification of the phases produced in the wall of the containers. Mössbauer spectroscopy and X-ray diffraction techniques were revealed as being an essential complement to the study.

The structure is composed of an austenitic matrix with a grain size of between 212 and $238 \mu \mathrm{m}$, near the internal and external faces of the wall, respectively, with numerous precipitates inside the grains and at the grain boundaries. The density of the precipitates decreases from the internal to the external surface. The precipitates are nitrides $(\mathrm{Cr}, \mathrm{Mo})_{12}$ $(\mathrm{Fe}, \mathrm{Ni})_{8-x} \mathrm{~N}_{4-z}$ near the internal surface and carbides $(\mathrm{Cr}$, $\mathrm{Fe}, \mathrm{Mo})_{23} \mathrm{C}_{6}$ in the other zones of the wall.

\section{Acknowledgements}

The authors are indebted to Sachs-Transmeca for providing fractured furnace containers and indicating operating conditions, and to Residual Stress Group, Department of Physics of the University of Coimbra, for the availability of its X-ray diffraction facilities.

\section{References}

[1] B. Mintz, A. Cowley, R. Abushosha, D.N. Crowther, Mater. Sci. Technol. 15 (10) (1999) 1179-1185.

[2] C.H. Lee, C.D. Lundin, Weld. J. 77 (1) (1998) 29s-37s.

[3] S. Heino, E.M. Knutson-Wedel, B. Karlsson, Mater. Sci. Technol. 15 (1) (1999) 101-108.

[4] ASM International Metals Handbook, Vol. 9, Metallography and Microstructures, 9th Edition, The Materials Information Society, 1995.

[5] B.F.O. Costa, S.M. Dubiel, Phys. Stat. Sol. (a) 139 (1993) 83.

[6] K.J. Kim, L.H. Schwarz, J. Phys. C 6 (37) (1976) 405.

[7] S.M. Dubiel, B.F.O. Costa, Phys. Rev. B 47 (1993) 12257.

[8] A.J.R. Loureiro, B.F.O. Costa, Mater. Sci. Technol. 16 (4) (2000) 436441.

[9] L.K. Singhal, J.W. Martin, Acta Metall. 16 (1968) 1441. 